\title{
Interactive comment on "Quantifying the range of the dust direct radiative effect due to source mineralogy uncertainty" by Longlei Li et al.
}

\section{Longlei Li et al.}

II859@cornell.edu

Received and published: 17 October 2020

We thank the reviewer much for the comments and criticism on this work. We have made changes to the manuscript where necessary. Text from the manuscript is quoted with double quotation marks. Please see figures/tables we created and cited here as Fig. R/Table $R$ in the supplement material.

\section{COMMENT}

Whereas, the paper appears comprehensive and includes many references, it doesn't discuss possibly the most related paper, that of Jacobson (2001). That study simulated the solar and thermal-IR global direct radiative forcing of several individual soil dust components, namely iron oxide, aluminum oxide, silicon dioxide, calcium carbonate, 
magnesium carbonate, potassium carbonate, and sodium carbonate, as well as soil dust as a whole. Of possible relevance, the present paper does not mention anywhere the role of absorption by aluminum in soil dust particles, Figure 4k of Jacobson (2001) indicates that aluminum may be a strong absorber in soil dust particles.

Ideally, the authors would include aluminum in their calculations. I realize this could result in having to redo their entire calculations. At a minimum, the authors need to discuss this omission and the potential impact on results. The authors also should mention that study in the context of its findings with regards to individual chemical components and the overall soil dust radiative impact in the solar and thermal-IR.

\section{RESPONSE}

Aluminum oxide is known as corundum in the mineralogy terminology. However, Jacobson (2001) is expressing aluminum, silicon and iron in minerals as component oxides. (Chemical analyses of minerals are customarily reported as weight percent's of component oxides.) For example, the mineral feldspar that we referred to in the manuscript is a group of rock-forming tectosilicate minerals. Being one of the alkali feldspar (a solid solution between two endmembers, potassium feldspar and albite), ( $\mathrm{Na0.87K0.13)Al1Si3O8} \mathrm{is} \mathrm{equivalent} \mathrm{to} \mathrm{the} \mathrm{combination} \mathrm{of} \mathrm{component} \mathrm{oxides} \mathrm{shown}$ in Table R1 (please note that we are using the figure/table number of our own as can be seen in each figure/table).

Therefore, our methodology cannot be directly compared to that of Jacobson (2001). What we model here are dust mineral species (illite, kaolinite, smectite, feldspar, iron oxides, etc.). In fact, these minerals could be equally expressed in terms of the weight percent of component oxides such as silicon dioxide, aluminum oxide, and iron oxide, as termed by Jacobson (2001).

Printer-friendly version

Besides this, while in nature there may be contributions of pure aluminum oxide (i.e., the mineral corundum) in dust, its contribution is very small, and it is not reported in any of the available soil mineralogical atlases that we used to compute dust aerosol 
mineralogy. As discussed below the absorption of aluminum oxide is negligible:

1) The absorption of pure crystal aluminum oxide that is present in dust aerosol particles would be negligible, in particular at the UV and visible bands, or at least significantly lower than that of iron oxides. We are not quite sure about what aluminum oxide refers to and the source of the optical constants used in Jacobson (2001). According to Table 2 of Toon and Pollack (1976), the imaginary complex refractive index (ImCRI) of pure crystal aluminum oxide approximates to an order of -7 at the UV and visible bands (as shown in Fig. R1), values much lower than that of iron oxides (an order between -1 and 1 at the visible Band 10 and UV Band 11 in CAM5/6). We obtained the wavelength-dependent $\mathrm{CRI}$ for dust minerals simulated by our models from Scanza et al. (2015) (please see supplement, Section S2 of that study), who compiled the $\mathrm{CRI}$ data from in-lab measurements. Toon and Pollack (1987) derived the CRI of pure crystal aluminum oxide based on measurements made at room temperature or 1200 celsius degree. As temperature increases, the absorption coefficient (related to the Im$\mathrm{CRI}$ ) for the pure crystal aluminum oxide can increase by dozens of times at the visible bands. But measurements at $3 \mu \mathrm{m}$, for example, show that the absorption coefficient does not substantially increase until temperature reaches $2000 \mathrm{~K}$ or above (Bityukov and Petrov, 2013) - a value well in excess of the upper limit of the Earth's atmospheric temperature.

2) The absorption by pure crystal aluminum oxide at infrared (IR) bands may not be as strong as minerals like quartz and feldspar that we considered in the manuscript for longwave dust direct radiative effect (DRE). For example, recently, Di Biagio et al. (2017) found that all the main absorption peaks at IR bands are contributions from either clays at $9.6 \mu \mathrm{m}$, quartz at 9.2 and $12.5-12.9 \mu \mathrm{m}$, kaolinite at $10.9 \mu \mathrm{m}$, calcite at $7.0 \mu \mathrm{m}$ and $11.4 \mu \mathrm{m}$, or feldspars at $8.7 \mu \mathrm{m}$ according to their in-situ measurements of dust spectral extinction coefficients. These measurements used soil samples selected from 137 available samples to be representative of the diversity of sources from arid and semi-arid regions at the global scale. The authors did not find contributions from 
aluminum oxide to the main absorption peaks at IR bands.

3) Currently, single scattering albedo (SSA) is believed to be the most important parameter that determines dust DRE at the top of the atmosphere. Previous studies (e.g., Engelbrecht et al., 2016; Moosmuller et al., 2012) and our results all show a clear relationship between iron oxide content (mass fraction of total dust) and the resultant SSA, (most evident at $0.405 \mu \mathrm{m}$ in Engelbrecht et al., 2016; at $0.405 \mu \mathrm{m}$ and $0.870 \mu \mathrm{m}$ in Moosmuller et al., 2012; at the band centered at $0.530 \mu \mathrm{m}$ in our manuscript). To our best knowledge, no publications exist showing a clear relationship between SSA and aluminum oxide content at either shortwave or longwave bands.

4) As stated in the manuscript, we normalized the mineral fractions, and our model setup probably underestimates the sensitivity of longwave DRE to the mineral content variation. Because of these, even for quartz and feldspar, our calculation suggests they do not have considerable impacts on quantifying longwave DRE uncertainty. Moreover, the amount of the mineral corundum in the dust aerosol should be tiny in nature, considering the total amount of $\mathrm{Al} 2 \mathrm{O} 3$ that can also come from a variety of other minerals (Table R1) we considered in the manuscript in dust is small, ranging between $0-15 \%$ (Figure 18b of Engelbrecht et al., 2016, which expressed the amount of Al in dust as Al2O3), in general, compared to quartz and feldspar. Consequently, the impact of omitting the mineral corundum, again whose absorption of longwave radiation is weak compared to quartz and feldspar, on the estimated longwave DRE range would be highly likely negligible as well.

Besides above discussions, we constructed a test in CAM5 with C1999 using the CRI of aluminum oxide reported by Toon and Pollack (1987) (Table 2 of that study and the data is shown in Fig. R1). Since the spatial distribution and uncertainty of corundum in the surface soil are unknown, we assume here they are the same as quartz in the silt-sized category. The amount (Fig. 1b of the preprint and Fig. 1e of Scanza et al. 2015 ) of high-bound quartz (the upper limit of the 95\% confidence interval of quartz in the corresponding soil category) is higher than that of hematite in either the clay-

Interactive comment
Printer-friendly version

Discussion paper 
or silt-sized category; so is the absolute deviation of high-bound quartz from the base (Fig. $1 \mathrm{~b}$ of the preprint); both the amount and the absolute deviation, thus, should be much higher than those of aluminum oxide or corundum in nature, the amount of which is tiny (please see point 4 above). Our assumption on the spatial distribution and uncertainty of aluminum oxide, thus, would highly likely exaggerate the impact of aluminum oxide on the estimated DRE uncertainty range. Despite the exaggeration, as can be seen in Fig. R2, the global mean deviation resulting from the assumed aluminum oxide uncertainty is still small, $-0.003 \mathrm{~W} \mathrm{m-2}$ and $+0.003 \mathrm{~W} \mathrm{m-2}$, for shortwave (Fig. R2a) and longwave (Fig. R2b with no 51\% augment) DRE, respectively. With the above assumptions, we conclude that the impact of aluminum oxide on the global DRE uncertainty range, is highly likely much smaller in amplitude than that caused by hematite (Fig. $5 \mathrm{a}$ of the preprint). This is also true spatially, if one compares Fig. R2a to Fig. 6a (preprint) for shortwave DRE (longwave dust DRE insensitive to variation of the mineral content within the uncertainty range).

Therefore, further inclusion of aluminum oxide (or pure crystal aluminum oxide) into our model would unlikely lead to a substantially change to the DRE range we estimated. Note again that what we modeled are minerals, and these minerals could be equally expressed in terms of the weight percent of component oxides such as silicon dioxide, aluminum oxide, and iron oxide (Table R1), as termed by Jacobson (2001).

\section{COMMENT}

Introduction. An additional impact of absorption by soil dust components is to contribute to cloud burn-off (Jacobson, 2012). Please discuss briefly.

\section{RESPONSE}

This is good point. Cloud burn-off occurs when dust and cloud are co-located due to absorption of shortwave radiation by dust which will increase diabatic heating and enhance cloud evaporation. Though the cloud burn-off effect of dust is outside the topic of this study, it's good to mention in the introduction for completeness. Following 
the reviewer's suggestion, we cited the work of Jacobson (2012) and modified relevant text in the introduction accordingly as follows:

"Dust aerosol (here defined as soil particles suspended in the atmosphere) perturbs the radiative energy balance directly by scattering and absorbing shortwave and longwave radiation known as the aerosol-radiation interaction (Boucher et al., 2013) and indirectly by changing the cloud albedo and lifetime by acting as cloud condensation nuclei (CCN) and ice nuclei (IN) (Nenes et al., 2014) and by increasing diabatic heating in the atmosphere and evaporating cloud (Hansen et al., 1997; Bollasina et al., 2008; Jacobson, 2012) known as the aerosol-cloud interaction (Boucher et al., 2013)."

\section{COMMENT}

Methods. "Two datasets currently exist. . ." Please clarify that FAO (1995) includes world soil data at $10 \mathrm{~km}$ resolution, and includes soil composition (SiO2, $\mathrm{CaCO}$, CaSO4, Fe2O3, Illite, Kaolinite, Smectite, Feldspars) in each data cell.

\section{RESPONSE}

When creating soil mineralogy map, we did not take information about soil composition from FAO but utilized its soil legend and location information to map soil atlases from C1999 and J2014. Please see the second paragraph of Section 2.1 in main text.

\section{COMMENT}

What is the source of solar- and thermal-infrared refractive index data for each chemical? It would be useful to see a plot of real and imaginary refractive indices of absorbing components versus wavelength.

\section{RESPONSE}

We took the refractive index data from Scanza et al. (2015), who collected and reported the high-resolution data in their supplement.

Following the Reviewer's suggestion, we created a new figure (Fig. R3) showing 
the $\mathrm{CRI}$ of each mineral against the shortwave and longwave bands implemented to $\mathrm{CAM} 5 / 6$. We show the $\mathrm{CRI}$ at each $\mathrm{CAM} 5 / 6$ band rather than the original highresolution wavelength reported by Scanza et al., (2015), because the former is more directly linked to our dust DRE calculation.

Correspondingly, in the revised manuscript, we added new text like below introducing the data source, as well as the newly added figure.

Interactive

"The refractive index of each mineral for each band implemented in CAM is derived from Scanza et al. (2015) and shown in Fig. R3 for CAM5/6."

Note the figure number "R3" would be changed in the text to reflect the real number it should be in the revised manuscript; the same applies to following text for the case that is in the same situation.

\section{COMMENT}

What is missing is a comparison of aerosol absorption optical depth with global satellite data. This would give a better idea of the realism of the results here.

\section{RESPONSE}

The model performance on simulating minerals and dust loading has been thoroughly evaluated by previous studies: CAMs in Scanza et al. (2015) for the mineralogy version, Kok et al. (2014a,b) for the new dust emission scheme; GISS ModelE2 in Perlwitz et al. (2015a,b); MONARCH in Pérez et al., (2011). The model-tuning method has been detailed in Albani et al. (2014). These references had already been cited in the preprint. So, we don't include them in the reference list here.

In the manuscript submitted, we had already compared the calculated radiative efficiency to observations near/over one of the major dust source regions, illustrated for North Africa on Fig. 9 (preprint). We also have pointed out in the methodology section that the volume averaging method we employed to compute the bulk dust optical properties is overestimating dust radiative absorption. Some other uncertainty sources 
which we did not explicitly account for have also been given in Appendix A of the preprint. All these would show the readers how our models may bias the results.

However, to account for the reviewer's comments, we compared the results of the baseline simulation with measurements on the dust surface concentration/deposition and with an integrated dust aerosol optical depth (DOD) obtained by Ridley et al. (2016). We also compared the absorbing AOD (AAOD) from our models with that derived from AErosol RObotic NETwork (AERONET) measurements. Please see the details in the paragraphs that follow.

1) We plotted up a new figure (Fig. R4) to evaluate our model performance by comparing the simulated dust surface concentration and deposition flux with station-based measurements as in Albani et al. (2014). Please see detailed descriptions on the observational data from that study. Here, we show dust concentration/deposition from the baseline simulation only. For other cases, similar results were yielded and thus not shown, as DOD is insensitive to mineral content variation at least within their uncertainties (generally a small perturbation to the total dust amount). So, a retuning procedure for experiment cases except for high- and low-bound DOD is unnecessary, and thus both the surface dust concentration and deposition remain almost unchanged.

2) We added a comparison (Fig. R5) of simulated DOD with that obtained by integrating DOD from MODIS, MISR, AERONET, and model ensembles over 15 regions ( $x$-axis labels of Fig. R5) as in Ridley et al. (2016).

3) In the result section (Section 3.2.2.2), to give another vision on our model performance, we added a comparison of the AAOD calculated from cases other than the "normalized" ones in Table R2 with that derived from AERONET measurements. There are no SSA constrains made in Ridley et al., (2016) for the 15 regions. SSA solely based on satellite retrievals are very likely subject to large uncertainty (Samset et al., 2018) for a large portion of areas with no station-based measurements available for calibration. Therefore, we did not compare with AAOD from satellite retrievals

Printer-friendly version

Discussion paper
Interactive

comment 
but only utilized the DOD constrains as one of the proxies for evaluation of the model performance.

Per 1) and 2) above, we added the following text in Section 2.3.1:

"The baseline model fairly well reproduced the magnitude of dust concentration and deposition at the bottom model layer compared to station-based measurements (see Albani et al., 2014 for detailed descriptions) (Fig. R4; correlation: R2=0.88, and 0.83, for the surface dust concentration and deposition flux, respectively, which are statistically significant at the $95 \%$ confidence level). Particularly over regions near the dust source, such as North Africa, the model fairly well agrees with observations, despite a more smoothing spatial distribution of those dust proxies in the simulation. Comparing with the seasonal DOD averaged over 15 regions obtained by Ridley et al., (2016), the baseline simulation appears to show an overestimate in general near dust source regions and fairly well reproduced seasonal cycle (Fig. R5) from the climatological side. Periods for the simulation (2007-2011) and DOD constrain (2004-2008) do not well coincide. Despite the inconsistency in period, this overestimate of DOD close to the source is probably not totally an artifact, considering that to match DOD of 0.03 the global tuning of the model tends to emit more dust to compensate unduly strong deposition during transport. For the other cases, the simulated dust cycle is similarly comparable with observations and thus is not shown. The similarity of the simulated dust cycle among the different cases except those for high- and low-bound DOD is because DOD is insensitive to the variation of the mineral content at least within the mineral's uncertainty range, which is generally a small perturbation to the total dust amount. Therefore, a retuning procedure for experiment cases except for high- and low-bound DOD is unnecessary, and the simulated dust concentration and deposition, thus, remain almost unchanged."

Per 3), We revised Section 3.2.2.2 of the manuscript as follows:

a) changed the title to: 
"Model to observation comparison: clear-sky radiative effect efficiency and absorbing aerosol optical depth"

b) interpreted new results concisely as below and shown in that section as well:

"The predicted absorbing AOD (AAOD) is well within one standard deviation $(\sigma)$ of AERONET observations in all the cases except CAM6 with high-bound iron oxides in J2014 (Table R2). However, over the AERONET sites, CAM5/6 systematically undershoot observational $A O D$ and with simulated values outside mean $\pm \sigma$ of the observation. The coincidence between predicted and observational AAOD accidently occurs, because, meanwhile, CAM5/6 overestimates the dust absorption of radiation near the $0.55 \mu \mathrm{m}$ band with the simulated SSA systematically below the observation. It is likely that the overestimated radiation absorption is due to the use of the volume averaging method to compute the optical properties of bulk dust from those of the minerals. However, we cannot exclude the possibility of the contamination in dust over the selected sites by other absorbing aerosols like the black carbon. Moreover, the method used to filter out the AEROENT sites where dust aerosol does not dominate over other aerosols in terms of the optical depth (DOD no greater than 0.5xAOD) relies on the accuracy in the simulated DOD and non-dust AOD. Consequently, a mismatch that potentially exists between simulated and observational DOD and non-dust AOD may cause the comparison less meaningful. There are no SSA constrains made in Ridley et al., (2016) for the 15 regions. Thus, a comparison on the AAOD is unachievable. We did not compare the modeled AAOD with that from satellite observations, because available AAOD solely based on satellite retrievals are very likely subject to large uncertainty (Samset et al., 2018) for a large portion of areas with no station-based measurements available for calibration."

\section{COMMENT}

Figure S1. Please specify the wavelength range of "shortwave" radiation assumed. Also, please define "high-bound hematite" and "high-bound dust" in the figure caption.

Printer-friendly version

Discussion paper
Interactive

comment 


\section{RESPONSE}

We specified the short and long wavelength ranges in the caption of Fig. S1 as follows.

"Short wavelength represents Bands 1-14 (band center range: 0.23-3.46 $\mu \mathrm{m}$ excluding the broad Band 14 centered at $8.02 \mu \mathrm{m}$ ), and long wavelength Bands 15-30 (band center: 3.46-514.29 $\mu \mathrm{m}$ ) implemented in CAM5/6. These definitions apply to the whole rest of this supplement without further notice."

We defined "high-bound hematite" and "high-bound dust AOD" as well in that caption:

"For the case with the high-bound hematite in the clay-sized category, the model was configured to use the soil mineralogy atlas containing the upper limit of the $95 \%$ confidence interval of hematite in the corresponding category. The high-bound DOD and the other cases with high-bound/low-bound terms in this supplement are similarly defined."

Similarly, in the main text, for clarity, we

1) specified the short and long wavelength range: "The radiative flux at each vertical model layer, at 19 (band center range: 0.22-4.36 $\mu \mathrm{m}$ ) and 14 (band center range: 0.23-3.46 $\mu \mathrm{m}$ excluding the broad Band 14 centered at $8.02 \mu \mathrm{m}$ ) shortwave bands (for CAM4 and CAM5/CAM6, respectively), and 16 longwave bands (band center range: 3.46-514.29 $\mu \mathrm{m}), \ldots "$

2) defined the "high-bound" term: "the high-bound hematite in the clay-sized category (a case with which the model utilized the soil mineralogy atlas that contains the upper limit of the $95 \%$ confidence interval of hematite in the corresponding category; the other high-bound or low-bound cases are similarly defined) ..."

COMMENT

Figure S2. Please provide the source of the data in the figure caption.

RESPONSE 
Added "in J2014" to the caption of Fig. S2.

COMMENT: references from the reviewer

FAO, Soil Map of the World, Land and Water Dev. Div., Rome, Italy, 1995.

Jacobson, M.Z., Global direct radiative forcing due to multicomponent anthropogenic and natural aerosols, J. Geophys. Res., 106, 1551-1568, 2001.

Interactive

comment

Jacobson, M.Z., Investigating cloud absorption effects: Global absorption properties of black carbon, tar balls, and soil dust in clouds and aerosols, J. Geophys. Res., 117, D06205, doi:10.1029/2011JD017218, 2012.

\section{RESPONSE}

Relevant references cited.

\section{References}

The references that had already been cited in the preprint are not included here.

Di Biagio, C., Formenti, P., Balkanski, Y., Caponi, L., Cazaunau, M., Pangui, E., Journet, E., Nowak, S., Caquineau, S., Andreae O, M., Kandler, K., Saeed, T., Piketh, S., Seibert, D., Williams, E. and Doussin, J. F. C.: Global scale variability of the mineral dust long-wave refractive index: A new dataset of in situ measurements for climate modeling and remote sensing, Atmos. Chem. Phys., 17(3), 1901-1929, doi:10.5194/acp-17-1901-2017, 2017.

Bityukov, V. K. and Petrov, V. A.: Absorption Coefficient of Molten Aluminum

Oxide in Semitransparent Spectral Range, Appl. Phys. Res., 5(1), 51-71, doi:10.5539/apr.v5n1p51, 2013.

Bollasina, M., Nigam, S. and Lau, K. M.: Absorbing aerosols and summer monsoon C12 
evolution over South Asia: An observational portrayal, J. Clim., 21(13), 3221-3239, doi:10.1175/2007JCLI2094.1, 2008.

Boucher, O., Randall, D., Artaxo, P., Bretherton, C., Feingold, G., Forster, P., Kerminen, V.-M., Kondo, Y., Liao, H., Lohman, U., Rasch, P., Satheesh, S., Sherwood, S., Stevens, B., Zhang, X.-Y., Lohmann, U., Rasch, P., Satheesh, S., Sherwood, S., Stevens, B. and Zhang, X.-Y.: Clouds and Aerosols, in Climate Change 2013: The Physical Science Basis. Contribution of Working Group I to the Fifth Assessment Report of the Intergovernmental Panel on Climate Change, edited by V. B. Stocker, T.F., D. Qin, G.-K. Plattner, M. Tignor, S.K. Allen, J. Boschung, A. Nauels, Y. Xia and P. M. Midgley, pp. 573-657, Cambridge University Press, United Kingdom., 2013.

Engelbrecht, J. P., Moosmüller, H., Pincock, S., Jayanty, R. K. M., Lersch, T. and Casuccio, G.: Technical note: Mineralogical, chemical, morphological, and optical interrelationships of mineral dust re-suspensions, Atmos. Chem. Phys., 16(17), 10809-10830, doi:10.5194/acp-16-10809-2016, 2016.

Hansen, J., Sato, M. and Ruedy, R.: Radiative forcing and climate response, J. Geophys. Res. Atmos., 102(D6), 6831-6864, doi:doi:10.1029/96JD03436, 1997. Holben, B. N., Eck, T. ., Slutsker, I., Tanre, D., Buis, J. P., Setzer, A., Vermote, E., Reagan, J. A., Kaufman, Y. J., Nakajima, T., Lavenu, F., Jankowiak, I. and Smirnov, A.: AERONETâĂŤA Federated Instrument Network and Data Archive for Aerosol Characterization, Remote Sens. Environ., 66, 1-16, doi:10.1007/BF03174421, 1998.

Jacobson, M. Z.: Investigating cloud absorption effects: Global absorption properties of black carbon, tar balls, and soil dust in clouds and aerosols, J. Geophys. Res. Atmos., 117(6), 1-25, doi:10.1029/2011JD017218, 2012.

Moosmuller, H., Engelbrecht, J. P., Skiba, M., Frey, G., Chakrabarty, R. K. and Arnott, W. P.: Single scattering albedo of fine mineral dust aerosols controlled by iron concentration, J. Geophsyical Res., 2006, 2004-2008, doi:10.1029/2011JD016909, 2012. 
Samset, B. H., Stjern, C. W., Andrews, E., Kahn, R. A., Myhre, G., Schulz, M. and Schuster, G. L.: Aerosol Absorption: Progress Towards Global and Regional Constraints, Curr. Clim. Chang. Reports, 4(2), 65-83, doi:10.1007/s40641-018-0091-4, 2018.

Toon, O. B., Pollack, J. B. and Khare, B. N.: The optical constants of several atmospheric aerosol species: ammonium sulfate, aluminum oxide, and sodium chloride, J. Geophys. Res., 81(33), 5733-5748, doi:10.1029/JC081i033p05733, 1976.

Please also note the supplement to this comment:

https://acp.copernicus.org/preprints/acp-2020-547/acp-2020-547-AC1-supplement.pdf

Interactive comment on Atmos. Chem. Phys. Discuss., https://doi.org/10.5194/acp-2020-547, 2020. 